\title{
Research on Poverty Alleviation in China Based on Big Data in the Context of COVID-19
}

\author{
Chenguang Zhang ${ }^{1,2}$, Guifa Teng ${ }^{1{ }^{*}}$ \\ ${ }^{I}$ School of Information Science and Technology, Agricultural University of Hebei, Baoding, Hebei, \\ China \\ ${ }^{2}$ School of Computer and Information Technology, Cangzhou Jiaotong College, Cangzhou, Hebei, \\ China \\ *Corresponding Author.
}

\begin{abstract}
Objectives: In order to alleviate the impact of COVID-19 on China's poverty alleviation work, this paper proposes a performance evaluation method and a recommendation algorithm for poverty indicator system suitable for China's national conditions based on big data technology. Methods: The evaluation method combines the precise advantages of Bayesian classifier and the full-volume processing characteristics of big data to comprehensively evaluate the past poverty alleviation achievements. The recommendation algorithm takes the poverty alleviation data over the years as the research object and realizes the construction method of the indicator system in the relative poverty stage. Results: The comparison with Pearson's correlation coefficient shows that the new evaluation method has more accurate confidence calculation ability. And compared with the classic ALS recommendation algorithm, the new recommendation algorithm has a more scientific and reasonable recommendation effect. Conclusions: Finally, the paper proposes relevant suggestions for the next stage of policy formulation, proves that medical and health conditions play an important role in supporting poverty alleviation.
\end{abstract}

Keywords: COVID-19, poverty alleviation, performance evaluation, recommendation algorithm, big data, medical and health

\section{Introduction}

COVID-19 has hit existing global public health governance systems with its long incubation period, high infection rate, long treatment cycle and self-healing of mild cases. ${ }^{1}$ Its outbreak spread worldwide and caused a global economic recession, with China's economic development also severely impacted. ${ }^{2}$ The epidemic has posed a dilemma to economic development, ${ }^{3}$ but also demonstrated the Chinese government's strong social governance capacity and superior medical and health conditions. ${ }^{4,5}$

Poverty exists in many countries in the world. ${ }^{6}$ As the first country to achieve the Millennium Development Goals of reducing poverty by half in poverty alleviation, ${ }^{7}$ China is now the second largest economy in the world, with a fast economic growth rate compared with the last century. ${ }^{8}$ In recent years, living standards in China's rural areas have improved greatly, thanks to the development of a large number of preferential policies covering education, health care, housing, infrastructure and other aspects. ${ }^{9,}{ }^{10}$ By 2020, all state-level poverty-stricken counties in China and all poor people should be lifted out of poverty according to the document, however, the end of absolute poverty does not mean the complete end of poverty alleviation work, poverty is still the main problem in the stage of relative poverty. At present, many poverty alleviation policies are limited to the theoretical stage and lack of technical support.

Association rules ${ }^{11}$ often used to analyze business models can be used to dig for connections among a vast array of disordered poverty indicators. It can be represented as a derivation from antecedent $\mathrm{A}$ to consequent $\mathrm{B}$, like $A \rightarrow B$. And "Support" and "Confidence" are its two units of measurement, like $\operatorname{Support}(A)=\{A\} /\{N\}$ and Confidence $(A \rightarrow B)=\{A, B\} /\{A\}$. Apriori ${ }^{12,13}$ and FP-Growth ${ }^{14}$ are two early classical algorithms in the early stage, and many improved algorithms have been developed since then. ${ }^{15-17}$ ISSN: 0010-8189

(C) CONVERTER 2021

www.converter-magazine.info 
Recommendation algorithm is a kind of information filtering technology, and its purpose is to provide personalized recommendation to users in a large amount of data. With the rapid increase of poverty alleviation data, the relationship between poverty indicators has become more and more complex. The poverty indicator system formulated by human resources has been unable to take into account the actual characteristics of all aspects, and has shown more and more deficiencies. In the face of massive data, recommendation algorithm is an important means of information filtering. Combining the traditional agricultural poverty alleviation work with the recommendation algorithm can make a more comprehensive and effective analysis of poverty indicators, so as to provide scientific theoretical support for the next stage of policy making.

Commonly used recommendation algorithms include "content-based filtering", "collaborative filtering" and "mixed mode filtering". Collaborative filtering recommendation algorithm is the most commonly used one. This algorithm was first proposed in 1992, ${ }^{18}$ and it can be divided into "user based" ${ }^{19}$ and "project based". ${ }^{20}$ The idea of "user-based" is as follows: (1) calculate the current user rating of an item $\operatorname{score}\left(u_{i}, s\right)$; (2) Calculate the similarity between the current user and the recommended user $\operatorname{sim}\left(u, u_{i}\right)$; (3) Calculate the recommendation score between the user to be recommended and the project $P_{u, s}=\sum_{u_{i} \in U} \operatorname{sim}\left(u, u_{i}\right) \times \operatorname{score}\left(u_{i}, s\right)$. The idea of "project-based" is as follows: (1) calculate a user's score for the current project $s c o r e\left(u, s_{i}\right)$; (2) Calculate the similarity between the current project and the project to be recommended $\operatorname{sim}\left(s_{i}, s\right)$; (3) Calculate the recommendation score between the user and the items to be recommended $P_{u, s}=\sum_{s_{i} \in S} \operatorname{score}\left(u, s_{i}\right) \times \operatorname{sim}\left(s_{i}, s\right)$. Similarity is generally calculated in three ways: (1)

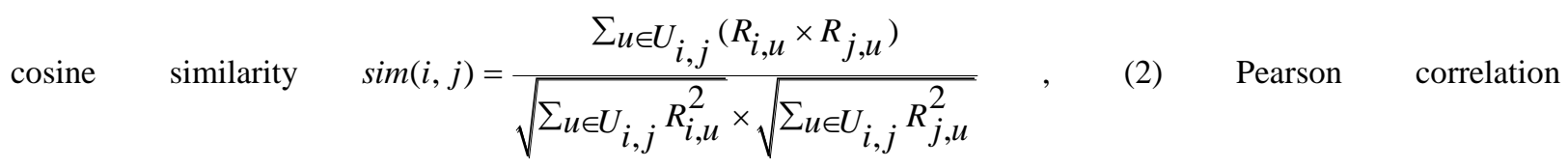
coefficient: $\quad \operatorname{sim}(i, j)=\frac{\sum_{u \in U_{i, j}}\left(R_{i, u}-\overline{R_{i}}\right) \times\left(R_{j, u}-\overline{R_{j}}\right)}{\sqrt{\sum_{u \in U_{i, j}}\left(R_{i, u}-\overline{R_{i}}\right)^{2}} \times \sqrt{\sum_{u \in U_{i, j}}\left(R_{j, u}-\overline{R_{j}}\right)^{2}}}$

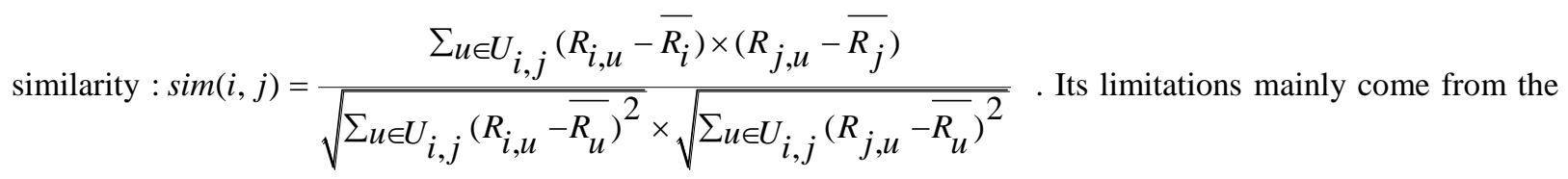
cold start problem: (1) the new user has no score record; (2) There is no scoring record for new projects; (3) Data sparsity.

\section{Framework}

This paper takes full account of the impact of COVID-19 on poverty alleviation in agriculture, and analyzes the huge role of medical and health conditions in the process of poverty alleviation. Article combines big data ${ }^{21}$ technology with agricultural poverty alleviation, and puts forward a performance evaluation method for poverty alleviation based on improved association rules, and a poverty indicator system construction method based on improved recommendation algorithm. Performance evaluation and indicator system will run through the whole process of poverty alleviation work.

The new performance evaluation method combines the precision advantage of Bayesian classifier with the full-volume characteristics of big data technology. This method solves the shortcoming that traditional association rules cannot be directly used in the process of agricultural poverty alleviation evaluation. Through the comparison

ISSN: 0010-8189

(C) CONVERTER 2021 
with Pearson correlation coefficient, it can be seen that this method has a more accurate evaluation effect on agricultural poverty alleviation data.

According to the actual characteristics of agricultural poverty alleviation work, the new recommendation algorithm puts forward some policy suggestions on the construction of poverty indicator system. Compared with ALS recommendation algorithm, this method has a better hierarchical evaluation effect on the importance of various agricultural poverty alleviation indicators, thus providing a scientific basis for the construction of poverty indic ator system.

Finally, based on the real poverty alleviation data of F County over the years, this paper verifies the performance of the two proposed poverty alleviation methods, and puts forward a scientific theoretical reference for the formulation of poverty alleviation policies in the next stage of this region according to the analysis results.

\section{Procedure}

3.1 Step 1: Implementation of performance evaluation method for poverty alleviation

It is difficult for traditional association rules to be directly applied in the field of agricultural poverty alleviation evaluation. Take Table 1 as an example, FP-Growth algorithm is used to conduct association rule analysis on it, so as to mine the correlation between various indicators.

Table 1 Rural annual per capita consumption expenditure data of $F$ country over the years (Yuan/person)

\begin{tabular}{|l|l|l|l|l|l|}
\hline Year & Food & Clothing & Education & Medical & Housing \\
\hline 2015 & 1830.62 & 358.37 & 450.95 & 537.19 & 1829.37 \\
\hline 2016 & 1872.72 & 514.29 & 457.26 & 543.64 & 1743.56 \\
\hline 2017 & 2157.77 & 576.63 & 560.15 & 634.29 & 2299.4 \\
\hline 2018 & 2246 & 607 & 622 & 823 & 2045 \\
\hline 2019 & 2528.16 & 701.17 & 730.8 & 957.94 & 2380.02 \\
\hline
\end{tabular}

As can be seen from the mining results in Table 2, the FP-Growth algorithm cannot effectively mine the correlation between indicators. Because indicators have the same name, number and weight, the root of the frequent spanning tree cannot be selected correctly and the frequent item sets cannot be generated.

Table 2 The frequent item sets mining results of the indicators

\begin{tabular}{|c|c|}
\hline Indicators & Frequent Item Sets \\
\hline$\{$ Education $\}$ & ([Education], 5) \\
\hline$\{$ Food $\}$ & ([Education, Food], 5) \\
\hline$\{$ Medical $\}$ & ([Education, Food, Medical], 5) \\
\hline$\{$ Clothing $\}$ & ([Education, Food, Medical, Clothing], 5) \\
\hline$\{$ Housing $\}$ & ([Education, Food, Medical, Clothing, Housing], 5) \\
\hline
\end{tabular}

The simulation data table is shown in Table 3. Where: Year represents the year, CE represents the total consumption expenditure per capita, I represents various indicators, and A represents the poverty rate. Data need to be normalized because the magnitude difference between indicators is usually large and difficult to calculate directly. The normalization is as follows: a) $y_{i j}=x_{i j} / C E_{i}$, b) $c e_{i}=C E_{i} / \sum_{i=1}^{m} C E_{i}$, c) $z_{i j}=y_{i j} \times c e_{i}$. With A as the main keyword and the data in the table in descending order, $\mathrm{Y}_{\mathrm{m}}$ is the year with the lowest poverty rate. 
Table 3 Analog Data Sheet

\begin{tabular}{|l|l|l|l|l|l|}
\hline Year & $\mathrm{CE}$ & $\mathrm{I}_{1}$ & $\cdots$ & $\mathrm{I}_{\mathrm{n}}$ & $\mathrm{A}$ \\
\hline $\mathrm{Y}_{1}$ & $\mathrm{CE}_{1}$ & $\mathrm{X}_{11}$ & $\cdots$ & $\mathrm{X}_{1 \mathrm{n}}$ & $\mathrm{A}_{1}$ \\
\hline$\cdots$ & $\cdots$ & $\cdots$ & $\cdots$ & $\cdots$ & $\cdots$ \\
\hline $\mathrm{Y}_{\mathrm{m}-1}$ & $\mathrm{CE}_{\mathrm{m}-1}$ & $\mathrm{X}_{\mathrm{m}-1,1}$ & $\cdots$ & $\mathrm{X}_{\mathrm{m}-1, \mathrm{n}}$ & $\mathrm{A}_{\mathrm{m}-1}$ \\
\hline $\mathrm{Y}_{\mathrm{m}}$ & $\mathrm{CE}_{\mathrm{m}}$ & $\mathrm{X}_{\mathrm{m} 1}$ & $\cdots$ & $\mathrm{X}_{\mathrm{mn}}$ & $\mathrm{A}_{\mathrm{m}}$ \\
\hline
\end{tabular}

According to Bayes' formula $P\left(x_{i j} \mid \bar{A}\right)=\frac{P\left(\bar{A} \mid x_{i j}\right) \times P\left(x_{i j}\right)}{P(\bar{A})}$, we know that formula $P\left(\bar{A} \mid x_{i j}\right)=\frac{P\left(x_{i j} \mid \bar{A}\right) \times P(\bar{A})}{P\left(x_{i j}\right)}$ holds. Set $P\left(x_{i j} \mid \bar{A}\right)=\mathrm{I}_{i, j}$, where: $1<=i<=m-1,1<=j<=n$ and $P\left(x_{i j} \mid A\right)=\mathrm{I}_{i, j}$, where: $i=m, 1<=j<=n$, formula $P\left(x_{i j}\right)=P\left(x_{i j} \mid \bar{A}\right) P(\bar{A})+P\left(x_{i j} \mid A\right) P(A)$ holds. $P\left(A \mid x_{i j}\right)$ Is denoted as poverty alleviation effect, the final trend of poverty is shown in Figure 1. According to the results, the level of poverty in the region has been decreasing year by year.

On this basis, the confidence matrix is constructed. The traditional formula of association rules can be expressed as $\operatorname{conf}(X \rightarrow Y)=\frac{\{X, Y\}}{\{X\}}$, according to the probability formula, the probability of occurrence of an event is proportional to the frequency of occurrence of an event. Therefore, the original formula can be expressed as $\operatorname{conf}(X \rightarrow Y)=\frac{f_{\{X, Y\}}}{N_{\{X\}}}$. If the consumption behavior of residents in the region meets two assumptions: (1) purchase in large quantities; (2) goods are purchased randomly, then residents' consumption behavior conforms to Bernoulli's theorem of large numbers, which can be expressed as $\lim _{n \rightarrow \infty} P\left\{\left|\frac{f_{\{X, Y\}}}{N_{\{X\}}}-P_{\{X, Y\}}\right|<\varepsilon\right\}=1$. At this point, the number formula for the frequent item set is transformed into the probability formula. The confidence formula of poverty alleviation evaluation indicator is set as $\operatorname{conf}(X \rightarrow Y)=\frac{\sum_{i=1}^{m}\left(X_{i}-\bar{X}\right)\left(Y_{i}-\bar{Y}\right)}{\sum_{i=1}^{m}\left(X_{i}-\bar{X}\right)\left(X_{i}-\bar{X}\right)}$, in this formula, the above part represents the degree of similarity between any two indicators, and the following part represents the degree of similarity between the indicator to be evaluated and itself. The coefficient $\frac{1}{m-1}$ is contemporaneously put into the upper and lower parts of the formula. At this point, the lower part becomes the unbiased estimation form $S^{2}=\frac{1}{m-1} \sum_{i=1}^{m}\left(X_{i}-\bar{X}\right)\left(X_{i}-\bar{X}\right)$ of sample variance, and the upper part becomes the unbiased estimation form $C \hat{o} v(X, Y)=\frac{1}{m-1} \sum_{i=1}^{m}\left(X_{i}-\bar{X}\right)\left(Y_{i}-\bar{Y}\right)$ of indicator correlation coefficient. However, the lower part of the confidence formula doubles itself in the process of calculating the degree of correlation, requiring the square root, so the final form of confidence is $\frac{\sqrt{m-1} \hat{\operatorname{cov}}(X, Y)}{\sqrt{S_{X}^{2}}}$. 


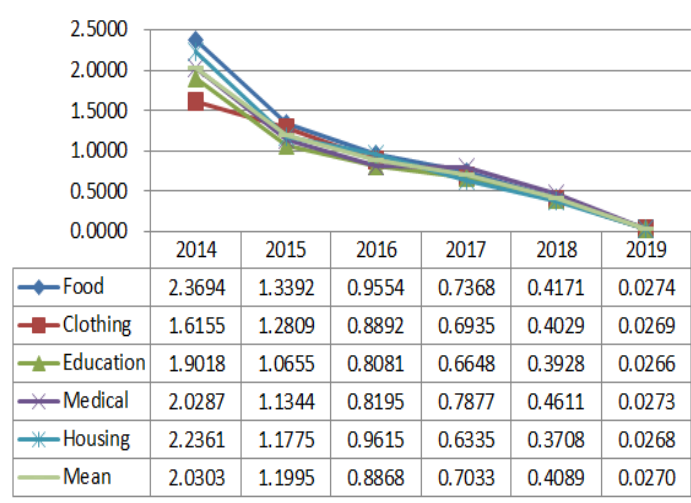

Fig 1: Chart of poverty over the years

3.2 Step 2: Construction of poverty indicator system

Through the evaluation method, we can know the promoting or inhibiting effect of various indicators on the performance of poverty alleviation in the past poverty alleviation process. On this basis, it is necessary to construct a suitable poverty indicator system according to the actual characteristics of the relative poverty stage, so as to provide a scientific basis for the policy formulation in the next stage. Evaluation and indicator system construction runs through the whole process of poverty alleviation work.

Assume that poverty alleviation data are available as shown in Table 4 . Where: $u_{i}, i \in[1, m]$ is the name of each poverty-stricken county, $I_{j}, j \in[1, n]$ is the name of each indicator. Set $U_{s u m}$ to be the sum of all indicators in a county, and $I_{\text {Sum }}$ to be the sum of an indicator in all counties.

Table 4 Simulated data table of each poverty-stricken county

\begin{tabular}{|c|c|c|c|c|}
\hline & $\mathrm{I}_{1}$ & $\cdots$ & $\mathrm{I}_{\mathrm{n}}$ & $\mathrm{U}_{\text {sum }}$ \\
\hline $\mathrm{u}_{1}$ & $\mathrm{R}_{11}$ & $\cdots$ & $\mathrm{R}_{1 \mathrm{n}}$ & $\mathrm{U}_{\mathrm{s} 1}$ \\
\hline$\cdots$ & $\cdots$ & $\cdots$ & $\cdots$ & $\cdots$ \\
\hline $\mathrm{u}_{\mathrm{m}}$ & $\mathrm{R}_{\mathrm{m} 1}$ & $\cdots$ & $\mathrm{R}_{\mathrm{mn}}$ & $\mathrm{U}_{\mathrm{sm}}$ \\
\hline $\mathrm{I}_{\mathrm{sum}}$ & $\mathrm{I}_{\mathrm{s} 1}$ & $\cdots$ & $\mathrm{I}_{\mathrm{sn}}$ & \\
\hline
\end{tabular}

Calculate the proportion of each data in rows and columns, as shown in Table 5. Among them, the left part (user-based $\mathrm{U}$ table) is in row statistics, and the right part (item-based I table) is in column statistics.

Table 5 Rows and columns averaging operation

\begin{tabular}{|c|c|c|c|c|c|c|c|}
\hline & $\mathrm{I}_{1}$ & $\cdots$ & $\mathrm{I}_{\mathrm{n}}$ & & $\mathrm{I}_{1}$ & $\cdots$ & $\mathrm{I}_{\mathrm{n}}$ \\
\hline $\mathrm{u}_{1}$ & $\mathrm{R}_{11} / \mathrm{U}_{\mathrm{s} 1}$ & $\cdots$ & $\mathrm{R}_{1 \mathrm{n}} / \mathrm{U}_{\mathrm{s} 1}$ & $\mathrm{u}_{1}$ & $\mathrm{R}_{11} / \mathrm{I}_{\mathrm{s} 1}$ & $\cdots$ & $\mathrm{R}_{1 \mathrm{n}} / \mathrm{I}_{\mathrm{sm}}$ \\
\hline$\cdots$ & $\cdots$ & $\cdots$ & $\cdots$ & $\cdots$ & $\cdots$ & $\cdots$ & $\cdots$ \\
\hline $\mathrm{u}_{\mathrm{m}}$ & $\mathrm{R}_{\mathrm{m} 1} / \mathrm{U}_{\mathrm{sm}}$ & $\cdots$ & $\mathrm{R}_{\mathrm{mn}} / \mathrm{U}_{\mathrm{sm}}$ & $\mathrm{u}_{\mathrm{m}}$ & $\mathrm{R}_{\mathrm{m} 1} / \mathrm{I}_{\mathrm{s} 1}$ & $\cdots$ & $\mathrm{R}_{\mathrm{mn}} / \mathrm{I}_{\mathrm{sm}}$ \\
\hline
\end{tabular}

For the convenience of later calculation, zero mean operation is carried out for each data, as shown in Table 6.

Table 6 Zero-meaning operations for rows and columns

\begin{tabular}{|c|c|c|c||c|c|c|c|}
\hline & $\mathrm{I}_{1}$ & $\cdots$ & $\mathrm{I}_{\mathrm{n}}$ & & $\mathrm{I}_{1}$ & $\cdots$ & $\mathrm{I}_{\mathrm{n}}$ \\
\hline $\mathrm{u}_{1}$ & $\mathrm{U}_{11}-\operatorname{Mean}\left(\mathrm{u}_{1}\right)$ & $\cdots$ & $\mathrm{U}_{1 \mathrm{n}}-\operatorname{Mean}\left(\mathrm{u}_{1}\right)$ & $\mathrm{u}_{1}$ & $\mathrm{I}_{11}-\operatorname{Mean}\left(\mathrm{I}_{1}\right)$ & $\cdots$ & $\mathrm{I}_{1 \mathrm{n}}-\operatorname{Mean}\left(\mathrm{I}_{\mathrm{n}}\right)$ \\
\hline$\cdots$ & $\cdots$ & $\cdots$ & $\cdots$ & $\cdots$ & $\cdots$ & $\cdots$ & $\cdots$ \\
\hline $\mathrm{u}_{\mathrm{m}}$ & $\mathrm{U}_{\mathrm{m} 1}-\operatorname{Mean}\left(\mathrm{u}_{\mathrm{m}}\right)$ & $\cdots$ & $\mathrm{U}_{\mathrm{mn}}-\operatorname{Mean}\left(\mathrm{u}_{\mathrm{m}}\right)$ & $\mathrm{u}_{\mathrm{m}}$ & $\mathrm{I}_{\mathrm{m} 1}-\operatorname{Mean}\left(\mathrm{I}_{1}\right)$ & $\cdots$ & $\mathrm{I}_{\mathrm{mn}}-\operatorname{Mean}\left(\mathrm{I}_{\mathrm{n}}\right)$ \\
\hline
\end{tabular}

ISSN: 0010-8189

(C) CONVERTER 2021 
Covariance was calculated for row data and column data as follows.

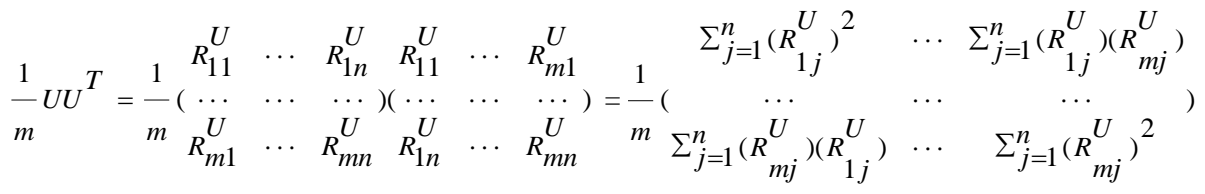

$$
\begin{aligned}
& \operatorname{var}\left(R_{1}^{U}\right) \quad \cdots \quad \operatorname{cov}\left(R_{1}^{U}, R_{m}^{U}\right) \\
& \begin{array}{ccc}
=\left(\begin{array}{ccc}
\cdots & \cdots & \cdots
\end{array}\right)_{m \times m} \\
\operatorname{cov}\left(R_{m}^{U}, R_{1}^{U}\right) & \cdots & \operatorname{var}\left(R_{m}^{U}\right)
\end{array}
\end{aligned}
$$

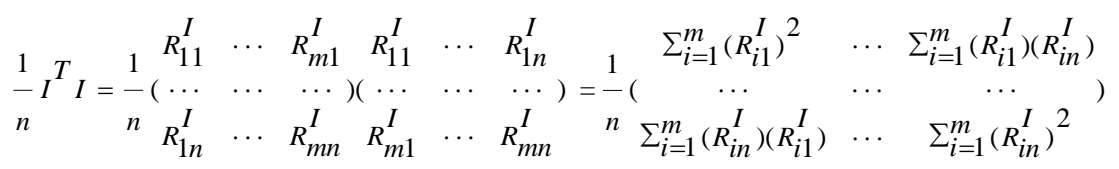

$$
\begin{aligned}
& \operatorname{var}\left(R_{1}^{I}\right) \quad \cdots \quad \operatorname{cov}\left(R_{1}^{I}, R_{n}^{I}\right) \\
& =\left(\begin{array}{ccc}
\cdots & \cdots & \cdots \\
\operatorname{cov}\left(R_{n}^{I}, R_{1}^{I}\right) & \cdots & \operatorname{var}\left(R_{n}^{I}\right)
\end{array}\right)_{n \times n}
\end{aligned}
$$

Since the covariance matrix is a symmetric matrix, the two covariance matrices are regarded as quadratic matrices and converted into quadratic equation as follows.

$$
\begin{aligned}
& Z_{u}=\operatorname{var}\left(R_{1}^{U}\right) \cdot u_{1}^{2}+\cdots+\operatorname{cov}\left(R_{1}^{U}, R_{m}^{U}\right) \cdot u_{1} \cdot u_{m}+\cdots+\operatorname{cov}\left(R_{m}^{U}, R_{1}^{U}\right) \cdot u_{m} \cdot u_{1}+\cdots+\operatorname{var}\left(R_{m}^{U}\right) \cdot u_{m}^{2} \\
& Z_{I}=\operatorname{var}\left(R_{1}^{I}\right) \cdot I_{1}^{2}+\cdots+\operatorname{cov}\left(R_{1}^{I}, R_{n}^{I}\right) \cdot I_{1} \cdot I_{n}+\cdots+\operatorname{cov}\left(R_{n}^{I}, R_{1}^{I}\right) \cdot I_{n} \cdot I_{1}+\cdots+\operatorname{var}\left(R_{n}^{I}\right) \cdot I_{n}^{2}
\end{aligned}
$$

In order to obtain the maximum value of covariance in each indicator, the partial derivatives of each indicator were calculated, and the results were as follows.

$$
\begin{aligned}
& \frac{\partial Z_{U}}{\partial u_{1}}=2 \cdot \operatorname{var}\left(R_{1}^{U}\right) \cdot u_{1}+\cdots+2 \cdot \operatorname{cov}\left(R_{1}^{U}, R_{m}^{U}\right) \cdot u_{m}+\cdots \\
& \cdots \\
& \frac{\partial Z_{U}}{\partial u_{m}}=\cdots+2 \cdot \operatorname{cov}\left(R_{1}^{U}, R_{m}^{U}\right) \cdot u_{1}+\cdots+2 \cdot \operatorname{var}\left(R_{m}^{U}\right) \cdot u_{m} \\
& \frac{\partial Z_{I}}{\partial I_{1}}=2 \cdot \operatorname{var}\left(R_{1}^{I}\right) \cdot I_{1}+\cdots+2 \cdot \operatorname{cov}\left(R_{1}^{I}, R_{n}^{I}\right) \cdot I_{n}+\cdots \\
& \cdots \\
& \frac{\partial Z_{I}}{\partial I_{n}}=\cdots+2 \cdot \operatorname{cov}\left(R_{1}^{I}, R_{n}^{I}\right) \cdot I_{1}+\cdots+2 \cdot \operatorname{var}\left(R_{n}^{I}\right) \cdot I_{n}
\end{aligned}
$$

Accordingly,

$$
\begin{gathered}
u_{i}=\frac{\sum_{j=1}^{m} \operatorname{cov}\left(R_{i}^{U}, R_{j}^{U}\right) \cdot u_{j}}{\operatorname{var}\left(R_{i}^{U}\right)}, 1<=i \neq j<=m \\
I_{i}=\frac{\sum_{j=1}^{n} \operatorname{cov}\left(R_{i}^{I}, R_{j}^{I}\right) \cdot I_{j}}{\operatorname{var}\left(R_{i}^{I}\right)}, 1<=i \neq j<=n
\end{gathered}
$$

This value is the similarity between various indicators, and the recommended equation is as follows. 
$P_{u, s}=\sum u_{i} \in U \cos \left(u, u_{i}\right) \cdot \operatorname{score}\left(u_{i}, s\right)$

$P_{u, s}=\sum_{s_{i} \in S} \cos \left(s, s_{i}\right) \cdot \operatorname{score}\left(s_{i}, u\right)$

Taking the simulated data in Table 7 as an example, the proposed recommendation algorithm was compared with ALS recommendation algorithm. ALS algorithm is very representative, and it is a hybrid filtering recommendation algorithm based on model. The basic idea is to decompose the sparse matrix by using the alternating least square method. Indicator data can be expressed as $R_{m \times n}=X_{m \times k} Y_{k \times n}^{T}$, where $k$ is far less than $m$ and $n$, to achieve the purpose of dimensionality reduction. In order to minimize the decomposition matrix error, the square error loss function $\min L(X, Y)=\min \sum\left(r_{u i}-x_{u}^{T} y_{i}\right)^{2}+\lambda\left(\left|x_{u}\right|^{2}+\left|y_{i}\right|^{2}\right)$ is required to be true. $x_{u}=\left(Y^{T} Y+\lambda I\right)^{-1} Y^{T} r_{u}$ and $y_{i}=\left(X^{T} X+\lambda I\right)^{-1} X^{T} r_{i}$ can be obtained by taking the derivative of $x_{u}$ and $y_{i}$ respectively. $R M S E=\sqrt{\frac{\sum\left(R-X Y^{T}\right)^{2}}{N}}$ is used for iterative calculation for error evaluation.

Table 7 Recommended algorithm simulation data table

\begin{tabular}{|c|c|c|c|c|}
\hline & $\mathrm{I}_{1}$ & $\mathrm{I}_{2}$ & $\mathrm{I}_{3}$ & $\mathrm{I}_{4}$ \\
\hline $\mathrm{u}_{1}$ & 2 & $?$ & 5 & $?$ \\
\hline $\mathrm{u}_{2}$ & $?$ & 3 & $?$ & 1 \\
\hline $\mathrm{u}_{3}$ & $?$ & 4 & $?$ & $?$ \\
\hline
\end{tabular}

The calculation results of the two recommendation algorithms are shown in Table 8. The similarities are as follows: (1) The new recommendation algorithm has the same coverage ability and can calculate the recommendation results between any two indexes; (2) The recommendation effect of the two algorithms is very close. The most obvious differences are: (1) I1 and I3 have different recommendations for U1. According to the calculation, the similarity between $\mathrm{U} 1$ and $\mathrm{U} 2, \mathrm{U} 1$ and $\mathrm{U} 3$ are 0 . Therefore, no matter what the score of $\mathrm{U} 1$ to I1 and I3 is, the result should be 0 . Therefore, the recommendation result of the new algorithm is more scientific. (2) Under the premise of the same effect, the recommended results of the new algorithm have more obvious polarization, because the partial derivative method is adopted, which leads to the increase of the results of the vector in a certain direction.

Table 8 Comparison of recommended results with ALS algorithm

\begin{tabular}{|c|c|c|c|c||c|c|c|c|c|}
\hline & $\mathrm{I}_{1}$ & $\mathrm{I}_{2}$ & $\mathrm{I}_{3}$ & $\mathrm{I}_{4}$ & $\mathrm{ALS}$ & $\mathrm{I}_{1}$ & $\mathrm{I}_{2}$ & $\mathrm{I}_{3}$ & $\mathrm{I}_{4}$ \\
\hline $\mathrm{u}_{1}$ & 0 & -6.217 & 0 & -0.918 & $\mathrm{u}_{1}$ & 1.998 & -1.632 & 4.995 & -0.615 \\
\hline $\mathrm{u}_{2}$ & -1.837 & 3.970 & -4.594 & 0 & $\mathrm{u}_{2}$ & -0.903 & 2.999 & -2.259 & 0.982 \\
\hline $\mathrm{u}_{3}$ & -1.730 & 2.977 & -4.325 & 0.992 & $\mathrm{u}_{3}$ & -0.761 & 3.997 & -1.904 & 0.944 \\
\hline
\end{tabular}

\section{Experimental results}

In order to verify the effectiveness of the proposed evaluation method and recommendation algorithm, this paper uses the real poverty alleviation data of F County over the years as the research object, and the data source is "China Statistical Yearbook".

The assessment method in section 3.1 is used to analyze the relevance of existing poverty alleviation indicators to determine the importance of each indicator. The results were compared with Pearson correlation coefficients, as shown in Table 9(a) and 9(b). Through comparison, it can be seen that the new evaluation method has more accurate evaluation ability and can provide more scientific data support for the next stage of policy making. The

ISSN: 0010-8189

C CONVERTER 2021

www.converter-magazine.info 
traditional evaluation method only uses the quantity as the criterion, but the new evaluation method combines the precise advantage of Bayesian classifier, by transforming the quantity problem into a probability problem, so that the discriminant results have a better hierarchical effect.

Table 9(a) The confidence results of new method

\begin{tabular}{|c|c|c|c|c|c|}
\hline Indicators & Food & Clothing & Education & Medical & Housing \\
\hline Food & $\times$ & $76.14 \%$ & $83.10 \%$ & $85.89 \%$ & $95.78 \%$ \\
\hline Clothing & $98.04 \%$ & $\times$ & $81.22 \%$ & $83.98 \%$ & $93.20 \%$ \\
\hline Education & $100.00 \%$ & $75.91 \%$ & $\times$ & $86.16 \%$ & $95.68 \%$ \\
\hline Medical & $99.57 \%$ & $75.62 \%$ & $83.01 \%$ & $\times$ & $94.96 \%$ \\
\hline Housing & $99.87 \%$ & $75.47 \%$ & $82.90 \%$ & $85.40 \%$ & $\times$ \\
\hline
\end{tabular}

Table 9(b) Comparison Results of Pearson Correlation Coefficients

\begin{tabular}{|c|c|c|c|c|c|}
\hline Indicators & Food & Clothing & Education & Medical & Housing \\
\hline Food & $\times$ & $97.93 \%$ & $99.89 \%$ & $99.46 \%$ & $99.75 \%$ \\
\hline Clothing & $97.93 \%$ & $\times$ & $97.63 \%$ & $97.26 \%$ & $97.06 \%$ \\
\hline Education & $99.89 \%$ & $97.63 \%$ & $\times$ & $99.78 \%$ & $99.65 \%$ \\
\hline Medical & $99.46 \%$ & $97.26 \%$ & $99.78 \%$ & $\times$ & $98.90 \%$ \\
\hline Housing & $99.75 \%$ & $97.06 \%$ & $99.65 \%$ & $98.90 \%$ & $\times$ \\
\hline
\end{tabular}

Through this evaluation method, the corresponding relationship between various poverty alleviation indicators and CPI is completed. It can be seen from the results that different indicators have different influences on CPI, the role of indicators in local economic development can thus be determined, as shown in Table 10. It can be seen from the results that all the indicators have a great impact on the medical CPI. This reflects the irrationality of the medical structure in the region and shows that medical consumption is an important factor contributing to the poverty of the population.

Table 10 the impact of various indicators on CPI

\begin{tabular}{|c|c|c|c|c|c|}
\hline & Food CPI & Clothing CPI & Education CPI & Medical CPI & Housing CPI \\
\hline Food & $\times$ & $0.78 \%$ & $-0.08 \%$ & $15.61 \%$ & $-2.47 \%$ \\
\hline Clothing & $-1.27 \%$ & $\times$ & $-0.11 \%$ & $15.62 \%$ & $-2.88 \%$ \\
\hline Education & $-1.21 \%$ & $0.87 \%$ & $\times$ & $15.16 \%$ & $-2.50 \%$ \\
\hline Medical & $-1.17 \%$ & $0.91 \%$ & $-0.08 \%$ & $\times$ & $-2.56 \%$ \\
\hline Housing & $-1.24 \%$ & $0.84 \%$ & $-0.05 \%$ & $15.79 \%$ & $\times$ \\
\hline
\end{tabular}

The recommendation algorithm in Section 3.2 makes use of the poverty alleviation data of several poverty-stricken counties over the years to obtain the recommendation results of various poverty indicators, thus providing a basis for the construction of poverty indicator system. The recommended results for each indicator are shown in Figure 2. L1: agriculture, forestry, animal husbandry and fisheries, L2: industry, L3: construction, L4: wholesale and retail, L5: transport, warehousing and postal services, L6: accommodation and catering, L7: information transmission, software and information technology services, L8: finance, L9: real estate, L10: leasing and business services, L11:scientific research and technical services, L12: water, environment and public facilities management, L13: residential services, repair and other services, L14: education, L15: social work, L16: culture, sports and recreation, L17: public administration, social security and social organization. 


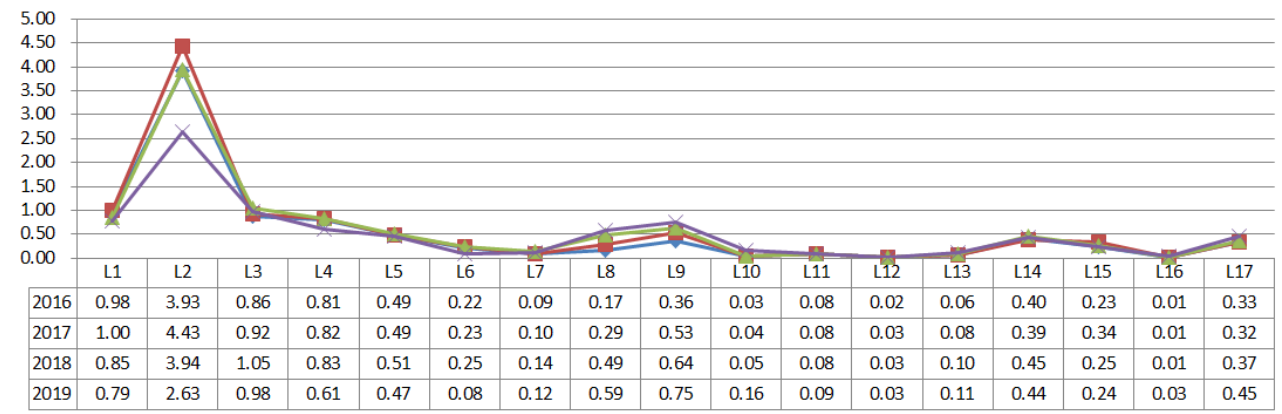

Fig 2: Recommended results of poverty indicators of F County

Through the analysis of the recommendation results, it can be seen that there is still room for further improvement in the demand for various indicators in F County, among which the industry, construction industry and agriculture, forestry, animal husbandry and fishery take the largest proportion, while the financial industry, real estate industry, leasing and commercial service industry have the fastest growth, while the accommodation and catering industry has a decreasing trend. One of the indicators can be refined by means of hierarchical analysis. Taking agriculture as an example, the detailed recommendations are as follows.

\subsection{Agricultural land}

The recommended results are shown in Figure 3. L1: arable land, L2: garden land, L3: woodland, L4: grassland, L5: land for agricultural facilities.

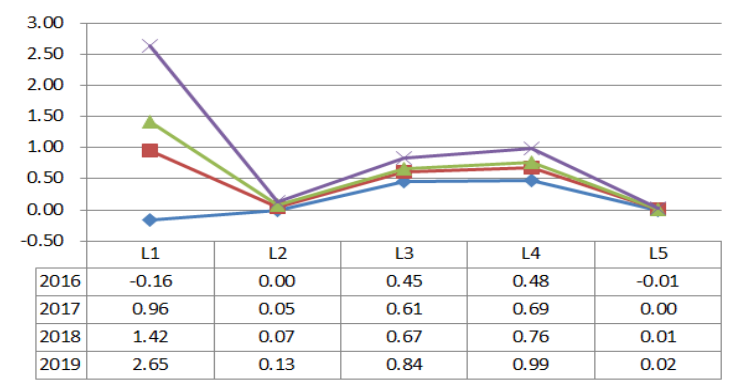

Fig 3: Recommended results of agricultural land

4.2 Agricultural mechanization

The recommended results are shown in Figure 4. L1: large tractor, L2: small tractor, L3: combine harvester, L4: power thresher, L5: water saving irrigation machine.

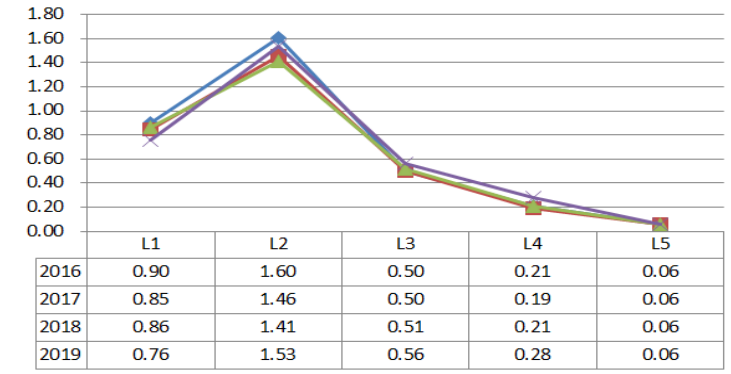

Fig 4: Recommended results of agricultural mechanization

4.3 The yield of agricultural food crops

The recommended results are shown in Figure 5. L1: cereals, L2: legumes, and L3: tubers.

ISSN: 0010-8189

(C) CONVERTER 2021

www.converter-magazine.info 


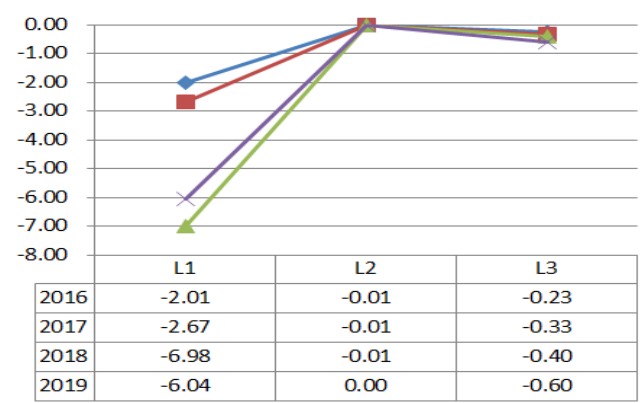

Fig 5: Recommended results of the yield of agricultural food crops

4.4 Output of agricultural cash crops

The recommended results are shown in Figure 6. L1: oil, L2: cotton, L3: tobacco, L4: Chinese herbal medicine, L5: vegetables and edible fungi, L6: melons and fruits.

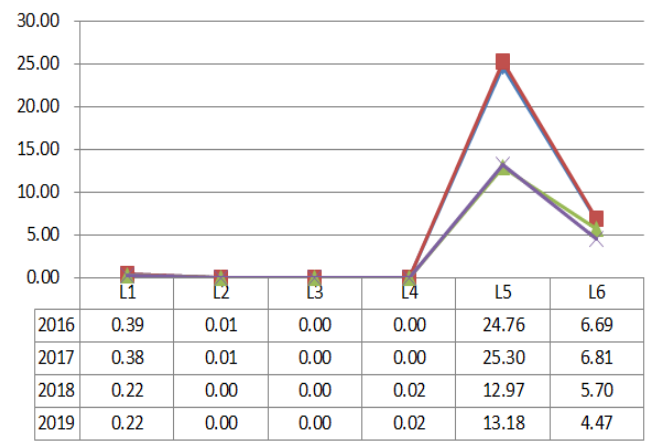

Fig 6: Recommended results of output of agricultural cash crops

\subsection{Output of Livestock and Poultry}

The recommended results are shown in Figure 7. L1: Pork, L2: Beef, L3: Lamb, L4: Poultry, L5: Eggs, L6: Dairy.

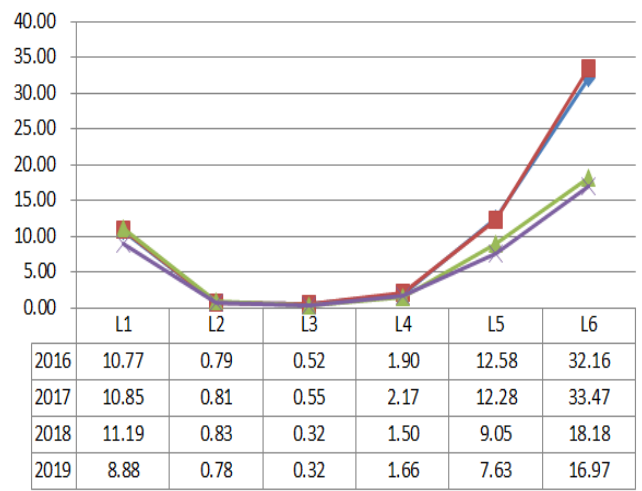

Fig 7: Recommended results of output of livestock and poultry

Through the analysis of the results of refined recommendation, the following conclusions can be drawn: (1) the proportion of cultivated land, woodland and grassland should be properly increased, so as to develop grain, economic wood and animal husbandry; (2) the proportion of small tractors, large tractors and combine harvesters should be appropriately increased; (3) Appropriately reduce the planting of cereals, beans and tubers, and increase the proportion of fruits, vegetables and edible fungi; (4) The consumption of livestock and poultry is dominated by dairy products, eggs and pork.

ISSN: 0010-8189 


\section{Policy Recommendations}

Through the analysis of the evaluation results, it can be seen that food, education and housing play a decisive role in the economic development of the region. At the same time, stability should be ensured in the areas of daily necessities and medical care. Combined with the results of the recommendation, it can be seen that the formulation of poverty alleviation policies in the next stage should conform to the following principles.

(1) Increase investment in industry. The crux of the problem of rural poverty lies in the problem of "agriculture, rural areas and farmers", and the development of industry can play a certain role in promoting the solution of this problem, specifically manifested in the following points. First, as China's industrial structure has gradually shifted to the new normal of "structural optimization and quality upgrading", urban-rural integration has also entered a stage of strategic transformation. The development of industry can provide employment opportunities and raise the incomes of the poor. Second, to develop industry is an effective way to bridge the gap between the rich and the poor between urban and rural areas, and also an effective means to maintain a medium-high growth rate of China's economy. Third, developing industry is an effective way to eliminate rural poverty, solve structural problems, avoid hollowing out rural areas and promote the construction of a new socialist countryside.

(2) Continue to increase investment in agriculture, forestry, animal husbandry, fishery and other areas. This area is the basis for rural residents to maintain their livelihood, and the rural revitalization strategy should be continuously improved by combining new ideas of poverty alleviation work. Based on the natural endowment and the actual advantages of rural areas, we will tap into the potential, develop a multi-dimensional poverty alleviation system, strengthen weak links, vigorously develop poverty alleviation through industry, and appropriately increase elimination mechanisms. Identify the root causes of poverty, help address issues related to agriculture, rural areas and farmers, and comprehensively advance the construction of a new socialist countryside.

(3) Increase support for the tertiary industry. Make good use of the role of science, education, culture, health and other fields in promoting poverty alleviation, vigorously develop tourism, catering, finance, wholesale and retail, and increase investment in public services and social security so that residents can gain a sense of happiness and identity.

(4) Stabilize and reduce health care prices. Reasonably improve the structure of the medical industry and strictly control inflation in the medical field. Enable residents to consume medical care.

\section{References}

[1] Kexin Wang. The Impact and Transformation of COVID-19 on Global Public Health Governance System. Advances in Social Sciences. 2021; 10(1):32-41

[2] Cheng Liu. The Macroeconomic Impact of the COVID-19. Statistics and Application. 2020; 9(5):862-869.

[3] Bitao Shi. Analysis about the Impact of COVID-19 Epidemic on Private Companies and Countermeasures - Taking Dongguan for Example. Advances in Social Sciences. 2020; 9(4):494-500.

[4] Yishun Zhou, Xi Wang. On the Manifesting and Refinement of Chinese National Governance Ability in the Prevention and Control for the COVID-19 Outbreak. Advances in Social Sciences. 2021; 10(1):157-164.

[5] Zhe Chen. Study of Government Governance in the Sudden Outbreak-Taking the COVID-19 as an Example. Open Journal of Legal Science. 2021; 9(1):74-80.

[6] Bapna Manish. World poverty: Sustainability is key to development goals. Nature. 2012; 489(7416).

[7] Mingyue Liu, Xiaolong Feng, Sangui Wang and Huanguang Qiu. China's poverty alleviation over the last 40 years: successes and challenges. Agricultural and Resource Economics. 2020; 64(1).

[8] International Fund for Agricultural Development. (2014). Rural poverty approaches, policies and strategies in China. Rome: IFAD.

ISSN: 0010-8189

(C) CONVERTER 2021 
[9] M. Rezaul Islam. Hunger Reduction in China: An Analysis of Contextual Factors. Asian Social Work and Policy Review. 2016; 10(3):295-310.

[10] Yansui Liu,Jilai Liu,Yang Zhou. Spatio-temporal patterns of rural poverty in China and targeted poverty alleviation strategies. Journal of Rural Studies. 2017; 52:66-75.

[11] Rakesh Agrawal,Tomasz Imieliński,Arun Swami. Mining association rules between sets of items in large databases. ACM SIGMOD Record. 1993; 22(2):207-216.

[12] R. Agrawal and R. Srikant. Fast algorithms for mining association rules in large databases, in 20 th Int. Conf. Very Large Data Bases (Santiago, Chile), Morgan Kaufmann Publishers Inc., San Francisco, CA, 1994; 487-489.

[13] Mateen R. Shaikh,Paul D. McNicholas,M. Luiza Antonie,Thomas Brendan Murphy. Standardizing interestingness measures for association rules. Statistical Analysis and Data Mining: The ASA Data Science Journal. 2018; 11(6):282-295.

[14] Jiawei Han,Jian Pei,Yiwen Yin. Mining frequent patterns without candidate generation. ACM SIGMOD Record. 2000; 29(2):1-12.

[15] Longtao Liu,Jiabao Wen,Zexun Zheng,Hansong Su. An improved approach for mining association rules in parallel using Spark Streaming. Circuit Theory and Applications. 2021; 1:1028-1039.

[16] Seyed Mohssen Ghafari,Christos Tjortjis. A survey on association rules mining using heuristics. Wiley Interdisciplinary Reviews: Data Mining and Knowledge Discovery. 2019; 9(4).

[17] N. Marín,M.D. Ruiz,D. Sánchez. Fuzzy frameworks for mining data associations: fuzzy association rules and beyond. Wiley Interdisciplinary Reviews: Data Mining and Knowledge Discovery. 2016; 6(2):50-69.

[18] David Goldberg,David Nichols,Brian M. Oki,Douglas Terry. Using collaborative filtering to weave an information tapestry. Communications of the ACM. 1992; 35(12):61-70.

[19] Yu Chuan,Xu Jieping,Du Xiaoyong. Recommendation algorithm combining the user-based classified regression and the item-based filtering. Electronic commerce. 2006:574-578.

[20] George Karypis. Evaluation of Item-Based Top- N Recommendation Algorithms. Information and knowledge management. 2001:247-254.

[21] Xueying Gu, Zhigang Shang, Xirong Guo. Analysis of the Application of Information Systems in the COVID-19 Epidemic under the Background of Big Data. Computer Science and Application. 2020; 10(12):2197-2204. 